\title{
Enhancing the Nutritional Quality of Vegetable Amaranth through Specific Food Preparation Methods
}

\author{
Winnie A. Nyonje ${ }^{1}$, Ray-Yu Yang ${ }^{2,3}$, Wan-Jen Wu ${ }^{2}$, Anselimo O. Makokha ${ }^{1}$, Willis O. Owino ${ }^{1}$ \& Mary O. \\ Abukutsa-Onyango ${ }^{4}$ \\ ${ }^{1}$ School of Food and Nutritional Sciences, Jomo Kenyatta University of Agriculture and Technology, Nairobi, \\ Kenya \\ ${ }^{2}$ Nutrition Unit, World Vegetable Centre, Shanhua, Taiwan \\ ${ }^{3}$ Food and Fertilizer Technology Center for the Asian and Pacific Region, Taipei, Taiwan \\ ${ }^{4}$ Department of Horticulture, Jomo Kenyatta University of Agriculture and Technology, Nairobi, Kenya \\ Correspondence: Winnie A. Nyonje, School of Food and Nutritional Sciences, Jomo Kenyatta University of \\ Agriculture and Technology, P.O. Box 62000-00200, Nairobi, Kenya. Tel: 254-723-363-401. E-mail: \\ winnienyonje2012@gmail.com
}

Received: June 30, 2021

Accepted: August 19, 2021

Online Published: August 26, 2021

doi:10.5539/jfr.v10n4p42

URL: https://doi.org/10.5539/jfr.v10n4p42

\begin{abstract}
Food preparation methods applied to African traditional vegetables vary greatly depending on preferences of various consumers. Vegetable amaranth is one of the most preferred vegetable, with high nutritional quality. The bioaccessibility of some minerals such as iron is, however, low since it is non-heme, and is also bound by anti-nutrients such as oxalates. This study aimed at evaluating the nutrient retention of amaranth vegetable dishes prepared using selected Kenyan traditional recipes, and to enhance the iron bioavailability of amaranth dishes using food preparation methods. Nutrient retentions of amaranth prepared by three common food methods were analyzed. In-vitro iron bioavailability of amaranth dishes with or without bioavailability enhancers as well as an amaranth meal incorporating a common maize meal staple food was also studied. The nutrient retentions of the various dishes used in this study was fairly high with at least $85 \%$ retention of minerals and an increase of up to $45 \%$ in three carotenoids. It can be concluded that incorporating vitamin $\mathrm{C}$, adding an iron rich vegetable and boiling of the vegetable significantly improves the iron bioavailability and hence improves the iron uptake by the body. Incorporating lemon juice enhanced dialysable iron of the selected recipe by up to $66 \%$. There was no significant $(\mathrm{P} \leq 0.05)$ effect by the amaranth components on the iron bioavailability of ugali. These methods could therefore be incorporated into household recipes to increase micronutrient intake.
\end{abstract}

Keywords: micronutrient malnutrition, bioaccessibility, anti-nutrients, ingredients

\section{Introduction}

The genus Amaranthus consists of many species, which are often considered as pseudo-cereals in Europe and America, but are mostly grown as vegetables in Africa (Achigan-Dako et al., 2014). It is considered as one of the African indigenous vegetables. The edible parts of the plants range from seeds, leaves and tender shoots. It is one of the most commonly consumed African indigenous vegetables in Kenya, East Africa and other parts of Africa (Kansiime et al., 2018). It is a cheap source of micronutrients that can contribute to reduced cases of micronutrient malnutrition. Apart from being a rich source of most micronutrients, amaranth is also a source of phytochemicals that are useful to the human body. In recent years, it is production has risen from that of a subsistence crop, to a commercial crop, finding itself on the shelves of most supermarkets in urban areas. In some case, supply cannot match demand (Cernansky, 2015). Its tender leaves and stem are used in many countries in Africa in the form of infusions, salads, sauces, soups; singly or mixed with other vegetables (Achigan-Dako et al., 2014).

This vegetable is, however, not consumed raw. It goes through food preparation methods which vary among consumers based on convenience and taste preferences rather than nutrient retention (Hossain et al., 2017). Preparation of these vegetables is done in different ways, according to the traditional recipes and culinary traditions of different communities (Musotsi, 2017). The general preparation process for African Indigenous 
vegetables involve sorting, destalking, washing and sometimes cutting (Musotsi et al., 2017), followed by varied cooking durations with unclear effects on the nutritional quality. These cooking methods induce a series of changes in physical properties, chemical properties and enzymatic modifications in various foods (Rothwell et al., 2015), affecting concentration and bioavailability of nutrients. Findings by different researchers on phytochemical and biological changes during cooking have been inconsistent and sometimes contradictory (Zhao et al., 2019). In order to maximize the nutritional benefits from amaranth vegetables, it is important to subject them to a cooking method that results in optimal nutrient retention and bioavailability (Habwe, 2012).

Despite the notable increase in consumption of indigenous vegetables including amaranth, micronutrient malnutrition still remains a public health problem in several parts of Africa, the most affected being children and women of child bearing age. In Kenya, $27.2 \%$ of women in reproductive age have anemia (Global Nutrition Report, 2019). In some areas of Kenya $76 \%$ of children have been reported to have been anemic at least at one point since birth (Kao et al., 2019). This hidden hunger could be linked to the high rates of morbidity and mortality among children and women especially in rural areas.

Though the common approach for combating iron deficiency anemia comprise supplementation and food fortification, diet modification and proper food preparation methods would be a cheaper and more sustainable approach. Modification of the diet may be done to improve nutritional value of common dishes and iron bioavailability. These may be through providing dietary information to include iron rich foods and improve cooking skills (Lion et al., 2018). Amaranth vegetable as a good source of dietary iron, can contribute to addressing the challenge of iron deficiency anemia. However, the bioavailability of the iron in amaranth is low due to its non-heme nature, as well as the presence of anti-nutrients such as oxalates which bind iron. This would result decreased absorption of most of the iron contained in the vegetable in the upper gut. Bioavailability of iron from a food source in the body is usually influenced by enhancers and inhibitors (Kapil, 2017). It has been noted that iron absorption in the upper gut can range from $1 \%$ to $40 \%$, and this can be doubled with certain cooking practices or by changing the composition of the meal such as by addition of other vegetables and fruits containing ascorbic acid (Kapil, 2017).

The aim of this study was to evaluate the nutrient retention of amaranth vegetable dishes prepared using some traditional recipes, and also to enhance the iron bioavailability of amaranth dishes using food preparation methods.

\section{Materials and Methods}

\subsection{Experimental Design and Treatments}

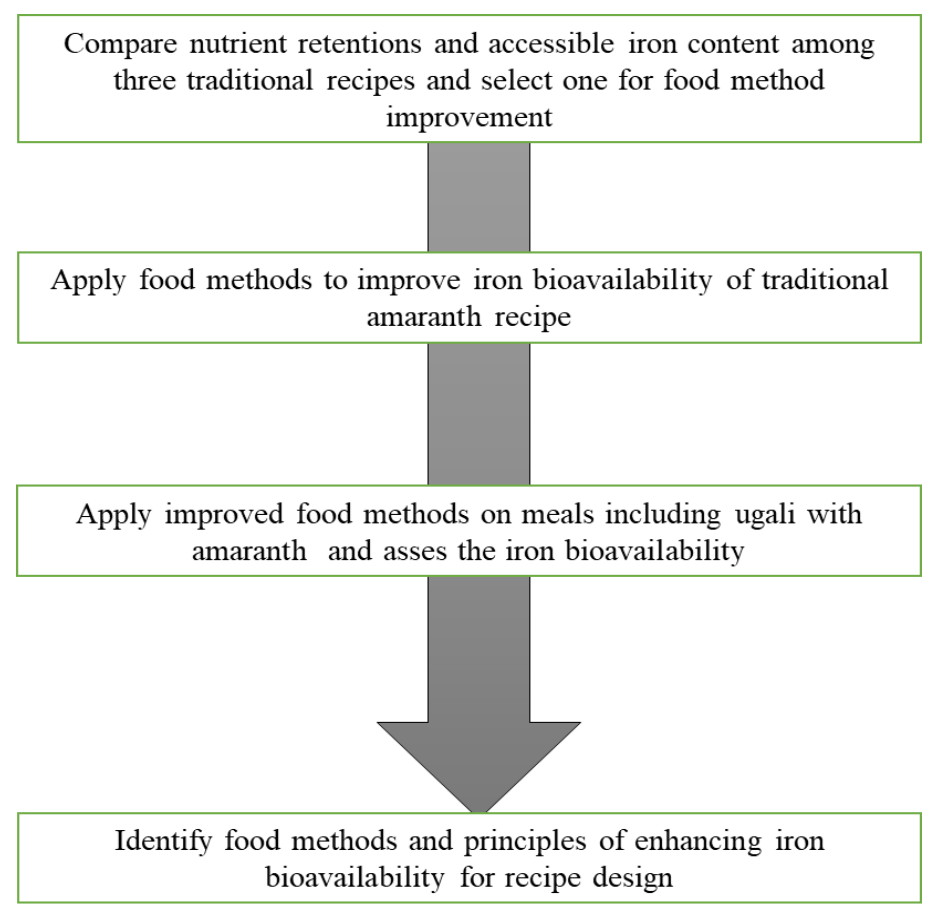

Figure 1. Summary of the study flow 
The study was carried out sequentially in three stages, involving different treatments at each stage. In the first stage, three traditional cooking methods were selected based on literature (Faber et al., 2010; Musotsi et al., 2005; Musotsi et al., 2017; Oluoch et al., 2012). Freshly harvested leaves were prepared using three (3) traditional recipes and fresh leaves (uncooked) as well as a mixture of the common ingredients used as control. The effect of cooking on retention of vitamins, minerals and oxalates, as well as the effect of cooking on iron bioavailability was determined. Thereafter, one of the selected recipes was chosen for improvement through use of iron bioavailability enhancers including high ascorbic acid ingredients (Blanco-Rojo \& Vaquero, 2019). The effect of boiling as well as addition of iron rich vegetables to amaranth iron bioavailability was also studied. At the third stage, the iron bioavailability of the traditional and improved cooking methods was analyzed in combination with a common staple, maize meal "ugali" (thick porridge).

\subsection{Experimental Material}

This study was carried out using three varieties of vegetable amaranth; Madiira 1(A. cruentus), Madiira 2 (A. cruentus) and AH-TL-Sel (A. hypochondriacus). These are improved varieties that were developed by World Vegetable Centre and released in Kenya and Tanzania. The vegetables were grown in the open field in Shanhua, Taiwan. Planting was done uniformly in trays and later transplanted into the open field after three weeks. Later the leaves were harvested uniformly at six weeks after planting, just before flowering. The edible parts (leaves and tender stems) were then separated and the vegetables from the three varieties mixed in the ratio 1:1:1. Other ingredients used in recipe preparation including onions, tomatoes, lemons and soybean oil were obtained from local supermarket in Shanhua, Taiwan. Moringa leaves were obtained from the World Vegetable Center in Taiwan, while maize flower was obtained from Kenya.

\subsection{Chemicals}

All reagents used were of analytical reagent (AR) grades. They included pepsin (P-7000, from porcine stomach mucosa), hydrochloric acid, pancreatin (P-1750, from porcine pancreas), bile extract (B-8631, porcine), Sodium hydrogen carbonate, sodium hydroxide, trichloroacetic acid (TCA), 4,7-diphenyl-1,10-phenanthroline disulfonic acid, hydroxylammoniumchloride, sodium acetate, $\mathrm{H}_{2} \mathrm{SO}_{4}$, standard oxalic acid, 2,4-dinitrophenylhydrazine (DNPH), 2,6-dichlorophenolindophenol (DCPIP), metaphosphoric acid thiourea standard L-(+)-ascorbic acid, Acetone, ethyl ether, methanol, potassium hydroxide, hexane, Tetrahydrofuran (THF). The chemicals were purchased from Merck and Sigma-Aldrich Co. (St. Louis, MO, USA).

\subsection{Preparation of Samples}

The fresh vegetables were destalked to separate edible portions comprising leaves and tender stems. All the vegetables used in the different experiments were washed with water then rinsed with distilled water. Onions and tomatoes were chopped into small pieces which were used for frying the vegetables. All the cooking was done in stainless steel pans over uniform heat on an electric cooker. The samples in the study are shown in Table 1. 
Table 1. Samples used in the study

\begin{tabular}{|c|c|}
\hline Sample & Description/ Preparation process \\
\hline \multicolumn{2}{|c|}{ Experiment 1: Nutrient retention and iron bioavailability among recipes } \\
\hline $\begin{array}{l}\text { Amaranth } \\
\text { Raw }\end{array}$ & These were freshly harvested amaranth leaves which were used as control reference in the study \\
\hline $\begin{array}{l}\text { Mixed } \\
\text { ingredients }\end{array}$ & $\begin{array}{l}\text { This was the uncooked control consisting of a mixture of amaranth leaves, onions, tomatoes, } \\
\text { and oil mixed together but with no cooking. The ratios of ingredients were the same as that used } \\
\text { for the cooked samples. The mixture was blended to ensure homogeneity }\end{array}$ \\
\hline Recipe 1 & $\begin{array}{l}\text { Approximately } 200 \mathrm{~g} \text { of fresh whole leaves (not chopped) were placed in } 200 \mathrm{~g} \text { of boiling } \\
\text { distilled water in a cooking pan. This was covered and let to boil for } 10 \text { minutes, stirring every } 3 \\
\text { minutes. The boiled vegetables were then stir-fried without straining in } 10 \mathrm{~g} \text { non-fortified } \\
\text { soybean oil, } 25 \mathrm{~g} \text { of chopped red bulb onions and } 25 \mathrm{~g} \text { chopped tomatoes for five minutes. }\end{array}$ \\
\hline Recip & $\begin{array}{l}\text { Approximately } 200 \mathrm{~g} \text { of fresh vegetables were chopped to medium size (about } 1 \mathrm{~cm} \text { wide) and } \\
\text { then placed in } 200 \mathrm{~g} \text { of boiling distilled water in a cooking pan. This was covered and let to boil } \\
\text { for } 10 \text { minutes, stirring every } 3 \text { minutes. The boiled vegetables were then stir-fried without } \\
\text { straining in } 10 \mathrm{~g} \text { non-fortified soybean oil, } 25 \mathrm{~g} \text { of chopped red bulb onions and } 25 \mathrm{~g} \text { chopped } \\
\text { tomatoes for five minutes }\end{array}$ \\
\hline Recipe 3 & $\begin{array}{l}\text { Approximately } 200 \mathrm{~g} \text { of fresh vegetables were chopped to medium size (about } 1 \mathrm{~cm} \text { wide) and } \\
\text { stir-fried in } 10 \mathrm{~g} \text { non-fortified soybean oil, } 25 \mathrm{~g} \text { of chopped red bulb onions and } 25 \mathrm{~g} \text { chopped } \\
\text { tomatoes for five minutes. This was without boiling. }\end{array}$ \\
\hline
\end{tabular}

\section{Experiment 2: Enhancing iron dialysability}

Improved This was prepared as the Recipe 1, with double the quantity of tomatoes $(50 \mathrm{~g}$ of chopped Recipe 1 with tomatoes). Components of tomatoes including vitamin $\mathrm{C}$ and lycopene have been reported to more tomato have positive effects on iron bioaccessibility (Garcia-Casal, 2006; Singh et al., 2016).

Improved This was prepared as Recipe 1, with one tablespoon $(10 \mathrm{~mL})$ of freshly squeezed lemon juice Recipe 1 with added. Lemon juice has been shown to increase iron bioavailability in foods (Singh et al., Lemon Juice 2016), and this is attributed to its ascorbic acid as well as other components

Samples for Two samples of $100 \mathrm{~g}$ fresh amaranth leaves were boiled in $200 \mathrm{~mL}$ distilled water for five boiling effect minutes. After boiling, excess water was discarded in one sample. This was also done with experiment another set of samples, with a boiling time of 15 minutes. Fresh amaranth leaves were used as control.

Samples for Three different samples of $100 \mathrm{~g}$ of amaranth, $100 \mathrm{~g}$ of fresh moringa leaves, and $100 \mathrm{~g}$ of a inclusion of mixture of amaranth leaves and moringa leaves (50:50); were boiled separately in $200 \mathrm{~mL}$ moringa distilled water for 5 minutes. The remaining water was not discarded. Dialysable iron was determined in these samples together with fresh amaranth and fresh moringa leaves to determine the effect of adding moringa, a high iron vegetable, on dialysable iron of an amaranth dish.

\section{Experiment 3: dializability of iron in amaranth meal combination}

Amaranth meals

Recipe 1 (Traditional recipe) and improved Recipe 1 with lemon were prepared. "Ugali” (thick porridge) was prepared using iron fortified maize flour from Kenya (Jogoo Maize Flour). Dialysable iron was determined for the two recipes, ugali, and a combination of ugali with each of the dishes in a ratio of $1: 1$.

\subsection{Nutrient Retention Analysis}

Determination was done for the nutritional components of the amaranth recipes as well as a mixture of all the ingredients (uncooked), and this was compared with the fresh amaranth sample. Components analyzed included oxalates, vitamin $\mathrm{C}$, minerals $(\mathrm{Ca}, \mathrm{Fe}$ and $\mathrm{Zn}$ ) and carotenoids (violaxanthin, lutein, $\alpha$-carotene and $\beta$-carotene)

\subsubsection{Determination of Oxalates}

Determination of oxalates was done by HPLC (Libert, 1981) with modifications suggested by Yu et al, (Yu et al., 2002). A $0.5 \mathrm{~g}$ fresh weight of sample was homogenized in $4 \mathrm{~mL}$ of $0.5 \mathrm{~N}$ HCL. The homogenate was heated at 
$80^{\circ} \mathrm{C}$ for 10 minutes with intermittent shaking. To the homogenate, distilled water was added up to a volume of $25 \mathrm{~mL}$. About $3 \mathrm{~mL}$ of the solution was withdrawn and centrifuged at $12000 \mathrm{rpm}$ for 10 minutes. About $1 \mathrm{ml}$ of supernatant was passed through a micro filter $(0.45 \mu)$ before HPLC analysis. Standards were prepared at varying concentrations for quantification. HPLC analysis was done using Shimadzu UV-VIS detector, Hypsil C18 column $(5 \mu \mathrm{M}, 4.6 \mathrm{~mm} * 250 \mathrm{~mm})$ equipped waters 550 was used as the static phase and the mobile phase was a solution $0.01 \mathrm{~N} \mathrm{H}_{2} \mathrm{SO}_{4}$. Flow rate was $0.6 \mathrm{~mL} \mathrm{~min}^{-1}$, pressure of $62 \mathrm{kgf}$ and detection wavelength of 221 nm.

\subsubsection{Determination of Vitamin C}

The vitamin $\mathrm{C}$ content was determined based on coupling 2,4-dinitrophenylhydrazine (DNPH) with ketonic groups of dehydroascorbic acid through the oxidation of ascorbic acid by 2,6-dichlorophenolindophenol (DCPIP), (Hanson et al., 2004). About 20 grams of blended samples were homogenized with $80 \mathrm{~mL}$ of $5 \%$ metaphosphoric acid and centrifuged at $7000 \mathrm{rpm}$ for 10 minutes. Two $\mathrm{mL}$ of the supernatant was transferred into $20 \mathrm{~mL}$ test tube followed by addition of $0.1 \mathrm{~mL}$ of $0.2 \% 2,6$-DCPIP sodium salt in water, $2 \mathrm{~mL}$ of $2 \%$ thiourea in 5\% metaphosphoric acid and $1 \mathrm{~mL}$ of $4 \%$ 2,4-DNPH in $9 \mathrm{~N} \mathrm{H}_{2} \mathrm{SO}_{4}$. The mixtures were kept in water bath at $37^{\circ} \mathrm{C}$ for $3 \mathrm{~h}$ followed by an ice bath for $10 \mathrm{~min}$. to the mixtures, $5 \mathrm{~mL}$ of $85 \%$ sulphuric acid was added and kept at room temperature for $30 \mathrm{~min}$ before reading at OD $520 \mathrm{~nm}$. Commercial L-(+)-ascorbic acid was used for calibration.

\subsubsection{Determination of Carotenoids}

Determination of carotenoids was done by HPLC (Rodriguez, 2001). About $0.1 \mathrm{~g}$ of freeze-dried sample was weighed into a vial. $0.6 \mathrm{~mL}$ distilled water and $4.4 \mathrm{~mL}$ Acetone was then added, mixed and shaken for $30 \mathrm{~min}$. The mixture was centrifuged and $2.0 \mathrm{~mL}$ of supernatant transferred to $10 \mathrm{~mL}$ test tube. Nitrogen gas was then used to dry the samples at $36^{\circ} \mathrm{C}$. Saponification was done by adding $100 \mu \mathrm{L}$ ethyl ether followed by $2.0 \mathrm{~mL}$ methanol and $1.0 \mathrm{~mL} \mathrm{15 \%} \mathrm{KOH}$ in methanol. The ethyl ether was evaporated using $\mathrm{N}_{2}$ gas and the samples incubated at $30^{\circ} \mathrm{C}$ while shaking for $2 \mathrm{~h} .3 \mathrm{~mL}$ of hexane and water $(1.5 \mathrm{~mL}$ water $+1.5 \mathrm{~mL}$ hexane) was added and mixed by shaking for $1 \mathrm{~min}$. The hexane layer was transferred to $60 \mathrm{~mL}$ separating funnel, collected 3 times and washed with water (4 times) then dried under nitrogen gas. To the dried sample, $100 \mu \mathrm{L}$ of Tetrahydrofuran (THF) and $1900 \mu \mathrm{L}$ Methanol (Merck LC grade) were added and mixed. The solution was then filtered through a $0.22 \mu \mathrm{m}$ membrane and $20 \mu \mathrm{L}$ injected into HPLC for analysis. Separation and identification of carotenoids was performed using HPLC system (Waters 2695, Milford, MA, USA) equipped with an auto-sampler, a photodiode array detector (Waters 996) monitoring at wavelength between $210-700 \mathrm{~nm}$. The static phase was a C 30 Column ( $\mathrm{YMC}^{\mathrm{TM}}$ Carotenoid $3.0 \mu \mathrm{m}, 4.6 \mathrm{~mm} \times 150 \mathrm{~mm}$ ). The running conditions were set at $30^{\circ} \mathrm{C}$ using a gradient at $1.3 \mathrm{~mL} / \mathrm{min}$ from $0 \%$ to $1 \%$ THF in methanol at $0-15 \mathrm{~min}, 1 \%$ to $25 \%$ THF in methanol at $15-25$ $\min , 25 \%$ to $70 \%$ THF in methanol at $25-50 \mathrm{~min}$, and the final $100 \%$ THF at $50-60 \mathrm{~min}$. Identification of sample carotenoids was performed by comparing retention time and light absorption spectra $(350 \mathrm{~nm}-700 \mathrm{~nm})$ of known standards. The peak areas were calibrated against known amounts of standards.

\subsubsection{Determination of Minerals}

Minerals were determined by strong acid digestion method and atomic absorption spectrophotometer (AAS) (AOAC, 2016). The minerals that were determined are calcium, iron and zinc. About $0.3 \mathrm{~g}$ of freeze-dried sample was mixed with $5 \mathrm{~mL}$ of $36 \mathrm{~N} \mathrm{H}_{2} \mathrm{SO}_{4}$ in a digestion flask. The flasks were placed in a digester and heated at $300^{\circ} \mathrm{C}$ for $2-3 \mathrm{~h}$. The contents were then cooled to about $150^{\circ} \mathrm{C}$ and $2 \mathrm{~mL}$ of $30 \%$ hydrogen peroxide $\left(\mathrm{H}_{2} \mathrm{O}_{2}\right)$ added. The tubes were placed in the digester at $300^{\circ} \mathrm{C}$ for further $30 \mathrm{~min}$ till the mixture was transparent. The mixture was then cooled to about $40^{\circ} \mathrm{C}$ and diluted with $50 \mathrm{~mL}$ distilled water. The absorbance of the solutions was read by Atomic Absorption Spectrophotometer (AAS) at their respective wavelengths. The various mineral standards were also prepared to make the calibration curve.

\subsection{Analysis of Iron Bioaccessibility}

\subsubsection{In-vitro Iron Dialysability Assay}

Dialysability of iron was determined using in vitro dialysability method (Luten et al., 1996) with simulated peptic and pancreatic digestion. A pepsin solution was prepared by dissolving $16 \mathrm{~g}$ of pepsin (P-7000, from porcine stomach mucosa) in $100 \mathrm{~mL}$ of $0.1 \mathrm{M} \mathrm{HCl}$. The pancreatin solution contained $4 \mathrm{~g}$ of pancreatin $(\mathrm{P}-1750$, from porcine pancreas) and $25 \mathrm{~g}$ of bile extract (B-8631, porcine) with $1000 \mathrm{~mL}$ of $0.1 \mathrm{M} \mathrm{NaHCO}_{3}$. The sample dry matter content was adjusted to 5 using distilled water, then homogenized. The $\mathrm{pH}$ of homogenized sample was adjusted to $\mathrm{pH} 2.0$ with $6 \mathrm{M} \mathrm{HCl}$, then $20 \mathrm{~g}$ was weighed into $125 \mathrm{~mL}$ conical flasks in three replications. Distilled water was also weighed in the same manner to act as blank. 
Peptic digestion- To $20 \mathrm{~g}$ of weighed samples, $0.75 \mathrm{~mL}$ pepsin solution was added. The mixture was covered well using parafilm and incubated at $37^{\circ} \mathrm{C}$ for $2 \mathrm{~h}$ with shaking.

Titratable acidity- To one replication of each digested sample, a titration was performed in which $20 \mathrm{~mL}$ of gastric digest was mixed with $5 \mathrm{~mL}$ of pancreatin-bile suspension and the amount of $0.5 \mathrm{M} \mathrm{NaOH}$ needed for this mixture to achieve a pH of $7 \pm 0.05$ was determined.

Pancreatic digestion- Segment of dialysis tubing $(6-8 \mathrm{~cm})$ was soaked in distilled water for about 30 minutes. A solution of $0.5 \mathrm{M} \mathrm{NaHCO}_{3}$, being equivalent to the volume of $0.5 \mathrm{M} \mathrm{NaOH}$ needed for the pancreatic digestion (titratable acidity), was made up to $25 \mathrm{~mL}$ with distilled water. These solutions were transferred into the dialysis tubes, tied on both sides, then placed into the conical flask containing gastric digest and incubated for 30 minutes at $37^{\circ} \mathrm{C}$. After 30 minutes, $5 \mathrm{~mL}$ of pancreatin-bile mixture was added and the incubation continued for another 2 hours. The dialysis tubes were then removed, washed in distilled water and the contents weighed. To $5 \mathrm{~mL}$ of dialysate, $2.5 \mathrm{~mL}$ of protein precipitant containing $10 \% \mathrm{TCA}$ and $10 \% \mathrm{HCl}$ in distilled water was added, heated in boiling water bath for 10 minutes and centrifuged at $10000 \mathrm{rpm}$ for 5 minutes.

To determine the dialysable iron, $3 \mathrm{~mL}$ of the supernatant was reacted with $2 \mathrm{~mL}$ of Bathophenanthroline reagent, containing $0.025 \%$ of 4,7-diphenyl-1,10-phenanthroline disulfonic acid and $10 \%$ hydroxylammoniumchloride in $2 \mathrm{M}$ sodium acetate. The mixture was let to stand for 15 minutes before reading at OD $535 \mathrm{~nm}$. Iron standard was used for calibration.

\subsection{Statistical Analysis}

The data collected was subjected to Analysis of Variance (ANOVA) using Genstat statistical software. Separation of means for the various treatments was done using Duncan's Multiple Range Test (DMRT).

\section{Results}

\subsection{Nutrient and Oxalate Retention of the Amaranth Dishes}

The nutrient contents of the various recipes were calculated on dry weight basis. The change in nutrient content was expressed as percentage of the mixed ingredients in raw form.

Table 2. Amounts of oxalates and Vitamin $\mathrm{C}$ in the recipes per $100 \mathrm{~g}$ DW

\begin{tabular}{lll}
\hline SAMPLE & OXALATE (mg) & VITAMIN C (mg) \\
\hline Amaranth raw & $2943^{\mathrm{c}}$ & $524.20^{\mathrm{c}}$ \\
Mixed Ingredients & $1720^{\mathrm{b}}$ & $244.93^{\mathrm{b}}$ \\
Recipe 1 & $1592^{\mathrm{a}}$ & $146.45^{\mathrm{a}}$ \\
Recipe 2 & $1605^{\mathrm{a}}$ & $172.98^{\mathrm{a}}$ \\
Recipe 3 & $1677^{\mathrm{b}}$ & $173.99^{\mathrm{a}}$ \\
LSD & 60.68 & 46.11 \\
\hline
\end{tabular}

Values are presented as Mean, $\mathbf{n}=\mathbf{3}$. Means within the same column with different superscripts were significantly $(P \leq 0.05)$ different. LSD $=$ Least Significant difference at $5 \%$ level of significance

There were significant $(\mathrm{P} \leq 0.05)$ differences in the oxalate contents of the various samples. The level of oxalates was lower in the cooked samples compared to the raw samples, with the lowest amounts detected in Recipe 1 (Table 2). Compared to the uncooked mixed ingredient recipe, cooking reduced the oxalate content. Recipe 3 , where there was no boiling, retained the highest oxalate content.

There was a reduction in vitamin $\mathrm{C}$ content in all the recipes. The amounts in the three recipes were, however, not significantly $(\mathrm{P} \leq 0.05)$ different. The vitamin $\mathrm{C}$ in the mixed ingredients was much lower than in fresh amaranth. This may be due to the loss of the vitamin through oxidation.

Table 3. Carotenoids content in the recipes in $100 \mathrm{~g}$ DW

\begin{tabular}{lllll}
\hline SAMPLE & $\begin{array}{l}\text { VIOLAXANTHIN } \\
(\mathbf{m g})\end{array}$ & $\begin{array}{l}\text { LUTEIN } \\
(\mathbf{m g})\end{array}$ & $\begin{array}{l}\boldsymbol{\alpha} \text {-CAROTENE } \\
(\mathbf{m g})\end{array}$ & $\begin{array}{l}\boldsymbol{\beta} \text {-CAROTENE } \\
(\mathbf{m g})\end{array}$ \\
\hline Amaranth raw & $8.37^{\mathrm{c}}$ & $47.64^{\mathrm{c}}$ & $2.39^{\mathrm{a}}$ & $22.65^{\mathrm{c}}$ \\
Mixed Ingredients & $4.06^{\mathrm{b}}$ & $23.52^{\mathrm{a}}$ & $1.93^{\mathrm{a}}$ & $12.65^{\mathrm{a}}$ \\
Recipe 1 & $0.00^{\mathrm{a}}$ & $33.51^{\mathrm{b}}$ & $2.35^{\mathrm{a}}$ & $18.20^{\mathrm{b}}$ \\
Recipe 2 & $0.00^{\mathrm{a}}$ & $34.29^{\mathrm{b}}$ & $2.38^{\mathrm{a}}$ & $18.13^{\mathrm{b}}$ \\
Recipe 3 & $3.30^{\mathrm{b}}$ & $31.75^{\mathrm{b}}$ & $2.60^{\mathrm{a}}$ & $16.77^{\mathrm{b}}$ \\
LSD & 0.93 & 3.96 & 0.62 & 2.03 \\
\hline
\end{tabular}


Values are presented as Mean, $\mathbf{n}=\mathbf{3}$. Means within the same column with different superscripts were significantly $(P \leq 0.05)$ different. LSD $=$ Least Significant difference at $5 \%$ level of significance

Four carotenoids were detected in the samples including violaxanthin, lutein, alpha carotene and beta carotene. The different carotenoids were affected differently by the different cooking methods. Violaxanthin was completely destroyed in the recipes that involved boiling, while the contents of the other carotenoids increased in the three recipes when compared to the mixed ingredients in raw form.

Table 4. Mineral contents of recipes in $100 \mathrm{~g}$ DW

\begin{tabular}{llll}
\hline SAMPLE & CALCIUM $(\mathbf{m g})$ & IRON $(\mathbf{m g})$ & ZINC (mg) \\
\hline Amaranth raw & $2403.09^{\mathrm{c}}$ & $30.15^{\mathrm{b}}$ & $4.42^{\mathrm{b}}$ \\
Mixed Ingredients & $1218.69^{\mathrm{a}}$ & $14.72^{\mathrm{a}}$ & $2.36^{\mathrm{a}}$ \\
Recipe 1 & $1322.81^{\mathrm{ab}}$ & $13.82^{\mathrm{a}}$ & $2.01^{\mathrm{a}}$ \\
Recipe 2 & $1418.10^{\mathrm{b}}$ & $12.59^{\mathrm{a}}$ & $2.12^{\mathrm{a}}$ \\
Recipe 3 & $1309.35^{\mathrm{ab}}$ & $13.91^{\mathrm{a}}$ & $2.30^{\mathrm{a}}$ \\
LSD & 141.10 & 4.00 & 0.43 \\
\hline
\end{tabular}

Values are presented as Mean, $\mathbf{n}=\mathbf{3}$. Means within the same column with different superscripts were significantly $(P \leq 0.05)$ different. LSD $=$ Least Significant difference at $5 \%$ level of significance

There were no significant $(\mathrm{P} \leq 0.05)$ differences the amounts of the various minerals among the three cooked recipes. The calcium content was slightly higher in all the recipes compared to the uncooked mixed ingredients, while iron and zinc contents were lower. However, these differences were not significant. Recipe 3 showed the lowest losses of iron and zinc.

\subsection{Iron Bioaccessibility in the Recipes}

The bioaccessible iron was calculated as the dialysable iron percentage of the total iron in each sample.

$$
\% \text { Bioaccessibility }=\frac{\text { Dialyzable iron }}{\text { Total iron }} \times 100 \%
$$

Table 5. Percentage Iron Bioaccessibility of the dishes

\begin{tabular}{ll}
\hline SAMPLE & \% Bioaccessibility \\
\hline Amaranth raw & $11.02^{\mathrm{a}}$ \\
Mixed Ingredients & $17.53^{\mathrm{b}}$ \\
Recipe 1 & $21.92^{\mathrm{bc}}$ \\
Recipe 2 & $24.22^{\mathrm{c}}$ \\
Recipe 3 & $21.59^{\mathrm{bc}}$ \\
LSD & 5.89 \\
\hline
\end{tabular}

Values are presented as Mean, $\mathbf{n}=\mathbf{3}$. Means within the same column with different superscripts were significantly $(P \leq 0.05)$ different. LSD $=$ Least Significant difference at $5 \%$ level of significance

The three preparation methods/recipes had higher iron dialysability compared to the raw sample. There were however no significant differences in iron dialysability among the dishes (Table 5).

\subsection{Enhancement of Dialysable Iron in Amaranth}

To improve dialysable iron and improve iron delivery from amaranth meals, further experiments were carried out to identify effects of preparation methods and some ingredients in enhancing iron dialysability in amaranth dishes. The methods that were considered for enhancement in this study were inclusion of high ascorbic acid ingredients as ascorbic acid enhances iron bioavailability; boiling (Blanco-Rojo \& Vaquero, 2019; Nomkong et al., 2019; Singh et al., 2016); and cooking the amaranth in combination with high iron vegetables as a way of increasing the total iron content.

The first experiment involved the addition of lemon juice, which is a source of vitamin $\mathrm{C}$ into the dish. Recipe 1 from the first experiment was chosen for this improvement. One recipe was made by doubling the amount of tomatoes used in the Recipe1 (Recipe 1+2X tomato), while another recipe was made by adding $10 \mathrm{~mL}$ fresh lemon juice to the Recipe 1 (Recipe $1+$ lemon juice), and comparing against the original Recipe 1. 


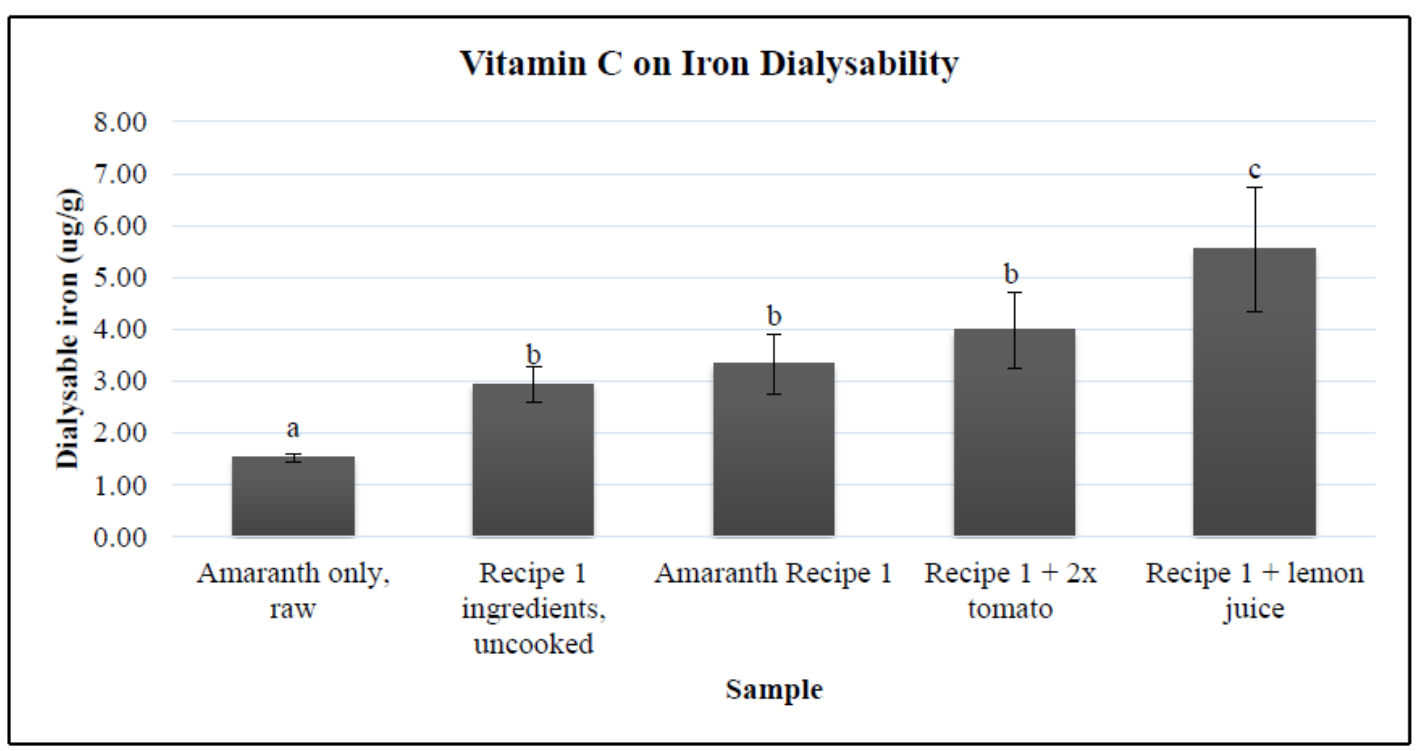

Figure 2. Effect of addition of Vitamin $\mathrm{C}$ rich ingredients on dialysable Iron of Amaranth recipes

Values are presented as Mean, $\mathbf{n}=\mathbf{3}$. Means with different superscripts were significantly $(P \leq 0.05)$ different .

The addition of lemon juice, a source of vitamin $\mathrm{C}$ had a positive effect on iron dialysability (Figure 2). Increase in the dialysable iron due to doubling the tomato content was, however, not statistically significant $(\mathrm{P} \leq 0.05)$ compared to the control recipe (Recipe 1). Adding lemon juice significantly $(\mathrm{P} \leq 0.05)$ enhanced dialysable iron of the traditional recipe (Recipe 1), compared to the raw amaranth. Lemon juice enhanced the dialysable iron by over $200 \%$ in comparison to the raw amaranth leaves, while the increase was $66 \%$ higher than the traditional recipe.

The effect of boiling on the iron dializability of amaranth was then determined. Studies on other vegetables have shown that boiling can enhance bioavailability of iron (Nomkong et al., 2019). While boiling led to an increase in dialysable iron, discarding excess water reduced the dialysable iron content. This could be attributed to the leaching of iron in the discarded water. Longer boiling (15 minutes) times increased dialysable iron compared to shorter boiling time (5 minutes).

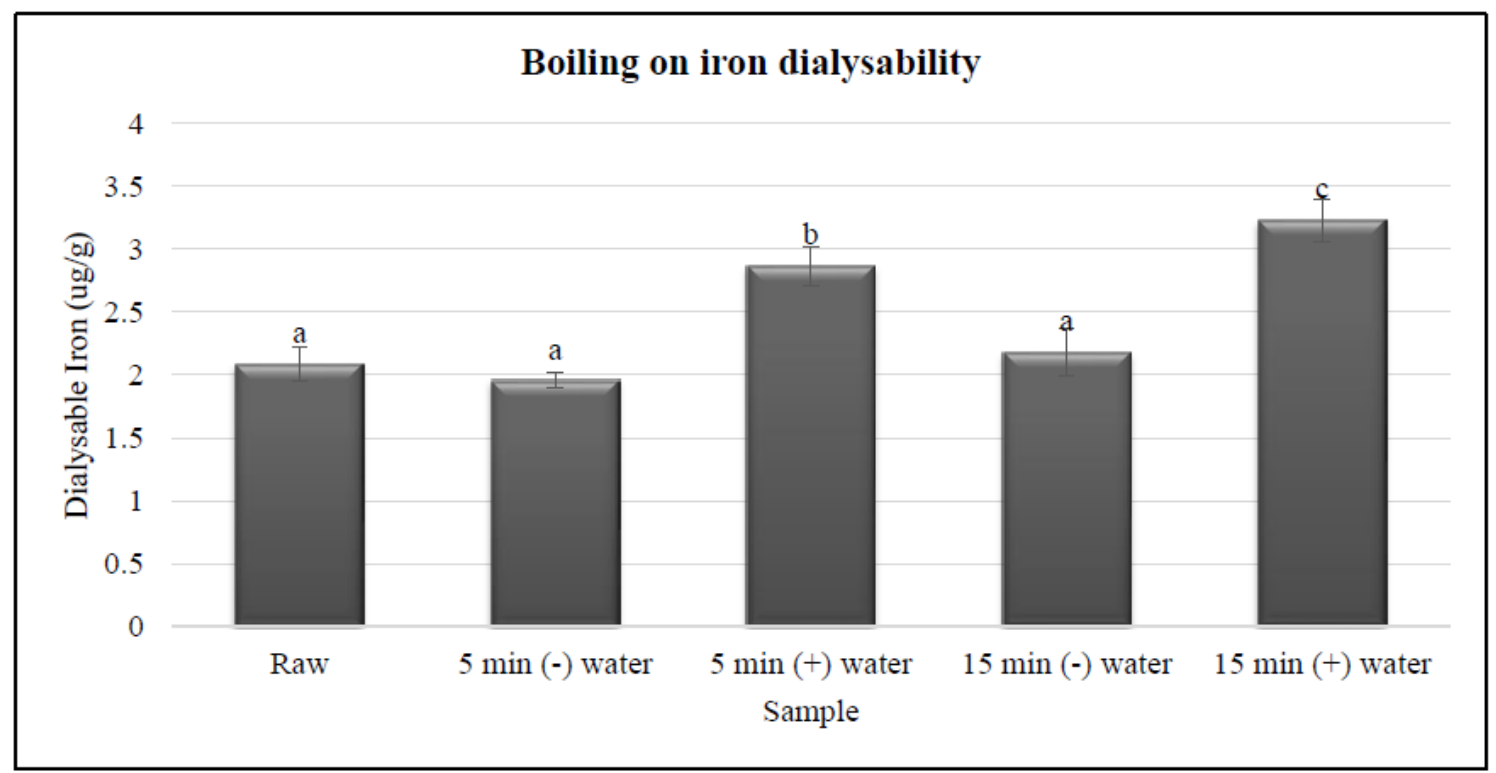

Figure 3. Effect of boiling and removal of excess water on iron dialysability of Amaranth

Values are presented as Mean, $\mathbf{n}=\mathbf{3}$. Means with different superscripts were significantly $(P \leq 0.05)$ different. 
Addition of moringa leaves also increased the quantity of dialysable iron of the amaranth. This could be partly because moringa has higher dialysable iron, and also because it contains higher amounts of vitamin $\mathrm{C}$, which is an enhancer (Gopalakrishnan et al., 2016; Shija et al., 2019).

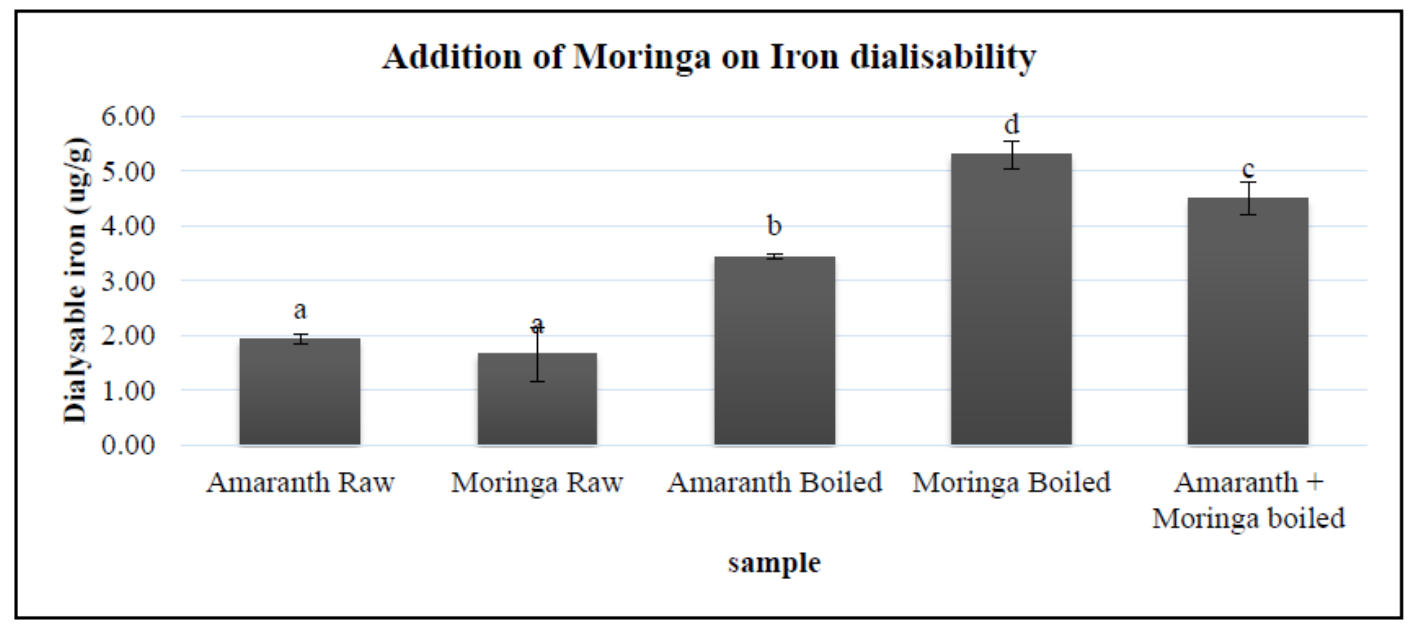

Figure 4. Effect of including Moringa leaves on iron dializability of Amaranth dish

Values are presented as Mean, $\mathbf{n}=\mathbf{3}$. Means with different superscripts were significantly $(P \leq 0.05)$ different.

The quantity of dialysable iron when the traditional recipe (Recipe 1) and improved recipe (Recipe 1 one with lemon juice) is combined with a common staple, Maize meal/Thick porridge ("ugali") was then determined to evaluate if the biochemical components of the cooked amaranth had any effect on the dialysable iron of the maize meal, which was iron fortified.

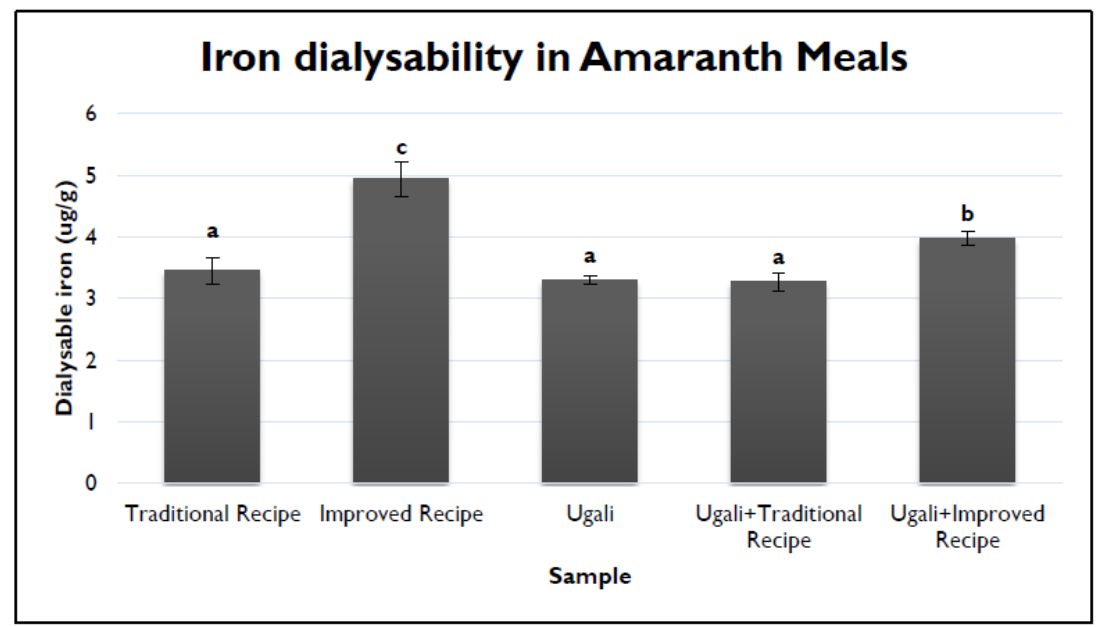

Figure 5. Iron dialyzability in traditional recipe and improved recipe in combination with maize meal Values are presented as Mean, $\mathbf{n}=3$. Means with different superscripts were significantly $(P \leq 0.05)$ different.

The improved recipe with lemon juice was used for this study in comparison with Recipe 1, and each was mixed with "ugali". Meal combination with improved recipe had significantly higher dialysable iron, at $21 \%$ more than the meal combination with the traditional recipe.

\section{Discussion}

African traditional vegetables form an important part of most diets in rural parts of Africa. Low consumption of micronutrient rich foods including green leafy vegetables has been reported to be associated with the incidence of mineral deficiencies. The minerals whose deficiency is of utmost public health concerns in East Africa are iron $(\mathrm{Fe})$, calcium $(\mathrm{Ca})$ and zinc $(\mathrm{Zn})$ (P. Singh \& Prasad, 2018). Despite the content of micronutrients in these 
vegetables, the preparation methods can greatly affect their bioavailability in the human body. Some anti-nutrients present in these vegetables such as oxalates may also bind to minerals hence reducing their bioavailability.

Oxalate, a major anti-nutrient in amaranth vegetables is not known to be heat sensitive; and its main reduction strategy could be by boiling and discarding of boiling water (Akhtar et al., 2011). This method can however, be counter-productive as most minerals and vitamins are also lost in the process. Recipe 1 and Recipe 2 in this study, both of which involved boiling, showed statistically significant reduction in the oxalate content (Table 2). The amount of oxalate in these two recipes were not significantly different, showing that there was no effect of chopping on the oxalate contents. The main effect of concern from oxalate is the interference with bioaccessibility of minerals including iron and calcium in the body. Even though many people can induct normal amounts of oxalate rich foods, people with certain conditions such as enteric hyperoxaluria need to lower their oxalate intake (Popova \& Mihaylova, 2019). In sensitive people, even small amounts of oxalate can cause burning in the eyes, ears, mouth and throat; while large amounts may cause abdominal pain, muscle weakness, nausea and diarrhea (Natesh et al., 2017).

During cooking, some nutritional components are reduced, which are mainly the vitamin components. For instance, a study conducted by Traore et.al., showed that boiling amaranth for 30 minutes completely destroyed the beta carotene in the vegetables (Traoré et al., 2017). All the recipes used in this study led to significant changes in the nutritional attributes of the dishes.

In this study, combination of size reduction or lack of it (chopping) with or without boiling (Table 2 and 3) retained statistically similar content of vitamin C, Iron and Zinc. This would have been due to the effect of the mixed ingredients which are known to contain these nutrients

Vitamin $\mathrm{C}$ was significantly reduced in the recipes compared to the raw ingredients by up to $40 \%$. The retention of vitamin $\mathrm{C}$ in recipes of this study was, however, much higher than those reported in other indigenous vegetable dishes such as 70\% and 93\% in African nightshade and spider plant, respectively (Musotsi et al., 2019). Vitamin $\mathrm{C}$ for example is easily lost during cooking since it is water soluble and temperature sensitive so it is easily degraded during cooking. Vitamin C cannot be synthesized by the body and therefore must be obtained from the diet (Singh \& Prasad, 2018), vegetables forming part of the best sources. The vitamin is a cofactor in numerous physiological reactions such as collagen gene expression, peptide hormone activation, carnitine synthesis, and it is also an effective antioxidant (Lee et al., 2018).

Carotenoids are essential in the human diet owing to their nutrition and health benefits. Apart from being a good source of pro-vitamin A, they also possess antioxidant activity, which helps lower the risks of long-term degenerative diseases. Their bioavailability can however be modulated using dietary factors such as mechanical disintegration, enzymatic maceration of matrix compounds, the addition of lipids, and thermal treatments (Schweiggert \& Carle, 2017). In this study, the amounts of carotenoids were much lower in the recipes compared to that in the fresh amaranth sample. However, compared to the mixed ingredients in raw form, three carotenoids, lutein, $\alpha$-carotene and $\beta$-carotene, were found to be enhanced by cooking, while violaxanthin, was not detected in recipes that included boiling. There was no significant $(\mathrm{P} \leq 0.05)$ difference in the carotenoid contents between the chopped and un-chopped samples. Cooking of vegetables has been reported to promote breakdown of the cellulose structures of the plant cell thereby releasing carotenoids. It also denatures carotenoid-protein complexes hence improving the extractability of the carotenoids in the cooked food (Miglio et al., 2008). It is also assumed that this enhanced extractability is associated with increased bioavailability of these compounds (Lee et al., 2018). Addition of lipids has also been shown to have a positive effect on carotenoid bioavailability (Schweiggert \& Carle, 2017). The use of oil in preparing the recipes in this study could have contributed to the release of more carotenoids from the matrix. Cooking was shown to enhance the carotenoid content in amaranth vegetables. There are also studies that show negative effect of cooking on carotenoids. The conflicting results could be due to differences in the starting materials as well as methodologies (Cilla et al., 2018), such as differences in the cooking time.

Minerals in vegetables such as calcium, iron and zinc are quite stable and not affected much by cooking. The iron and zinc contents of the three recipes in this study were not significantly different from that of the uncooked ingredients. There was, however, some increase in calcium content compared to the raw ingredients especially in Recipe 2 (Table 4). This increase can be attributed to release of complexes which are normally formed between calcium and other compounds such as oxalates. Similar results of slight increase in calcium contents on various species of amaranth and other leafy vegetables have also been reported (Amalraj \& Pius, 2014).

In-vitro assays have been used to estimate the bioaccessible nutrients from different food products. These assays 
mimic the digestive system, with the various enzymes as well as the conditions of the digestive tract controlled. Dialysis tubing is used to determine the amount of iron released from the food matrix, hence recorded as the dialysable iron.

In most foods especially those of plant origin such as amaranth vegetables, the iron concentration may not indicate its bioaccessibility (Amagloh et al., 2017). In this study (Table 4), the iron content of the raw amaranth was much higher than that in the recipes. However, the percent dialysable iron of the recipes was, however, higher than that of the raw amaranth (Table 5). One of the factors that can affect the bioaccessibility of this vegetable iron is their non-heme nature. The non-heme iron mostly exists in complexes, which can be degraded in the gastrointestinal tract during digestion owing to the action of pepsin and hydrochloric acid. Once released from food components, most non-heme iron is present in the ferric form $\left(\mathrm{Fe}^{3+}\right)$, with low solubility and bioavailability (Han, 2011). Another factor that is known to reduce the bioaccessibility of iron in amaranth leaves is oxalate which binds divalent minerals such as iron hence reducing their bioaccessibility. During cooking, iron is released from the complexes, and some ingredients such as tomatoes used in cooking may also enhanced the bioaccessibility of the iron (Nomkong et al., 2019). In this study, cooking involving boiling and heating during frying may have enhance the bioaccessibility of the iron. On the other hand, cooking itself softens the food matrix, releasing bound components, and also alters inherent mineral absorption inhibitors such as soluble dietary fiber thus improving their bioaccessibility (Platel \& Srinivasan, 2015).

This study clearly shows that food preparation methods such as boiling of the vegetables may be used to improve the bioaccessible iron significantly. For instance, inclusion of ingredients that are rich in ascorbic acid results in higher amounts of bioaccessible iron. This is because these vitamin $\mathrm{C}$ rich dietary components are capable of reducing the ferric iron to bioaccessible ferrous iron (Blanco-Rojo \& Vaquero, 2019). Enhancing effects of vitamin C on mineral bioaccessibility has also been observed in other studies (Singh \& Prasad, 2018). In this study, lemon juice was used as a source of vitamin $\mathrm{C}$, and this showed significant improvement in the bioaccessible iron. Other organic acids in the lemon juice such as citric acid could also be responsible for the enhancement of iron dializability. These acids are reported to have the ability of chelating iron to form soluble complexes. They also have the ability to lower $\mathrm{pH}$ increases solubilization of iron from the food (Rodriguez-Ramiro et al., 2019)

Inclusion of ingredients which are equally rich in iron also proved to be beneficial in improving the dialysable iron content. As most indigenous vegetables have also been shown to be good sources of iron, including them as ingredients could also result in higher iron content in the dish, hence higher bioaccessible iron. Moringa oleifera leaves in this study were used to determine if the anti-nutritional effects of oxalate in amaranth can be masked by including more iron in the dish. Moringa leaves have previously been reported to be rich in iron; Suzana et al reported values of $14.6 \mathrm{mg} / 100 \mathrm{~g}$ leaf extract, this being up to four times higher than spinach (Suzana et al., 2017); while Yang reported values of $9.2 \mathrm{mg} / 100 \mathrm{~g}$ fresh leaves (Yang et al., 2006). Other iron rich vegetables can also be included in amaranth recipes to increase the total iron in the vegetable dishes. Kruger et al., reported that combining of amaranth with spider plant (80:20 ratio) increased iron bioavailability of the dish from $9.7 \%$ to $25 \%$, while combination of amaranth with cowpea leaves (80:20 ratio) slightly increased iron bioavailability from $9.7 \%$ to $10.1 \%$ (Kruger et al., 2015).

Combination of amaranth Recipe1 with "ugali" (50:50) did not result in any significant difference in dialysable iron compared to the Recipe1 alone. In most parts of East Africa, amaranth dishes are eaten in combination with maize meal "ugali", which is either fortified or unfortified. This study evaluated meal interactions which would affect iron bioavailability and showed that components in amaranth did not have any inhibitory effects on the iron bioavailability of the iron-fortified maize meal.

\section{Conclusion}

The amaranth dishes prepared using the three different recipes all showed high nutrient retentions. Food based methods such as incorporating high vitamin $\mathrm{C}$ foods and high iron foods as ingredients in vegetable preparation significantly enhanced the dialysable iron in the amaranth based recipes, which translated to improvement in the bioavailable iron in the recipes. Use of such methods can be applied in increasing micronutrient intake and reduction of prevalence of micronutrient malnutrition.

\section{Acknowledgement}

We acknowledge the financial support from the German Federal Ministry for Economic Cooperation and Development (BMZ) commissioned and administered through the Deutsche Gesellschaft für Internationale Zusammenarbeit (GIZ) Fund for International Agricultural Research (FIA), provided under the Amazing Amaranth Project. We also appreciate the assistance of personnel at the Nutrition Unit, World Vegetable Centre 
in Taiwan. We also appreciate the Jomo Kenyatta University of Agriculture and Technology for the opportunity and their support in this work.

\section{References}

Achigan-Dako, E. G., Sogbohossou, O. E. D., \& Maundu, P. (2014). Current knowledge on Amaranthus spp.: Research avenues for improved nutritional value and yield in leafy amaranths in sub-Saharan Africa. Euphytica, 197(3), 303-317. https://doi.org/10.1007/s10681-014-1081-9

Akhtar, M. S., Israr, B., Bhatty, N., \& Ali, A. (2011). Effect of cooking on soluble and insoluble oxalate contents in selected Pakistani vegetables and beans. International Journal of Food Properties, 14(1), 241-249. https://doi.org/10.1080/10942910903326056

Amagloh, F. K., Atuna, R. A., Mcbride, R., Carey, E. E., \& Christides, T. (2017). Nutrient and Total Polyphenol Contents of Dark Green Leafy Vegetables, and Estimation of Their Iron Bioaccessibility Using the In Vitro Digestion/Caco-2 Cell Model. Foods, 6(54), 1-12. https://doi.org/10.3390/foods6070054

Amalraj, A., \& Pius, A. (2014). Bioavailability of calcium and its absorption inhibitors in raw and cooked green leafy vegetables commonly consumed in India \&\#x02013; An invitro study. In FOOD CHEMISTRY. Elsevier Ltd. https://doi.org/10.1016/j.foodchem.2014.08.031

AOAC. (2016). Official Methods of Analysis (20th ed.). Association of Official Analytical Chemists International.

Blanco-Rojo, R., \& Vaquero, M. P. (2019). Iron bioavailability from food fortification to precision nutrition. A review. Innovative Food Science and Emerging Technologies, 51, 126-138. https://doi.org/10.1016/j.ifset.2018.04.015

Cernansky, R. (2015). The rise of Africa's super vegetables. Nature, 522(7555), 146-148. https://doi.org/10.1038/522146a

Cilla, A., Bosch, L., Barberá, R., \& Alegría, A. (2018). Effect of processing on the bioaccessibility of bioactive compounds - A review focusing on carotenoids, minerals, ascorbic acid, tocopherols and polyphenols. Journal of Food Composition and Analysis, 68, 3-15. https://doi.org/10.1016/j.jfca.2017.01.009

Faber, M., Oelofse, a, Van Jaarsveld, P. J., Wenhold, F. a M., \& Jansen van Rensburg, W. S. (2010). African leafy vegetables consumed by households in the Limpopo and KwaZulu-Natal provinces in South Africa. South African Journal of Clinical Nutrition, 23(1), 30-38. https://doi.org/10.1080/16070658.2010.11734255

Garcia-Casal, N. (2006). Carotenoids increase iron absorption from cereal based food in the humans. Nutr Res, 26, 340-344. https://doi.org/10.1016/j.nutres.2006.06.015

Global Nutrition Report. (2019). Country overview: Malnutrition burden. Global Nutrition Report. Retrieved from https://globalnutritionreport.org/resources/nutrition-profiles/africa/eastern-africa/kenya/

Gopalakrishnan, L., Doriya, K., \& Kumar, D. S. (2016). Moringa oleifera: A review on nutritive importance and its medicinal application. Food Science and Human Wellness, 5(2), 49-56. https://doi.org/10.1016/j.fshw.2016.04.001

Habwe, F. (2012). Food Preparation and Processing Methods on Nutrient Retention and Accessibility in Selected Indigenous Vegetables from East Africa.

Han, O. (2011). Molecular mechanism of intestinal iron absorption. Metallomics, 3(2), 103-109. https://doi.org/10.1039/c0mt00043d

Hanson, P. M., Yang, R. Y., Wu, J., Chen, J. T., Ledesma, D., Tsou, S. C. S., \& Lee, T. C. (2004). Variation for antioxidant activity and antioxidants in tomato. Journal of the American Society for Horticultural Science, 129(5), 704-711. https://doi.org/10.21273/jashs.129.5.0704

Hossain, A., Khatun, M. A., Islam, M., \& Huque, R. (2017). Enhancement of antioxidant quality of green leafy vegetables upon different cooking method. Preventive Nutrition and Food Science, 22(3), 216-222. https://doi.org/10.3746/pnf.2017.22.3.216

Kansiime, M. K., Ochieng, J., Kessy, R., Karanja, D., Romney, D., \& Afari-Sefa, V. (2018). Changing knowledge and perceptions of African indigenous vegetables: the role of community-based nutritional outreach. Development in Practice, 28(4), 480-493. https://doi.org/10.1080/09614524.2018.1449814

Kao, J., Mutuku, F., Martin, S., Lee, J., Mwandi, J., Mukoko, D., Malhotra, I., King, C. H., \& LaBeaud, A. D. (2019). Early childhood anemia in a birth cohort in coastal Kenya: Links to infection and nutrition. 
American Journal of Tropical Medicine and Hygiene, 101(1), 242-252. https://doi.org/10.4269/ajtmh.17-0688

Kapil, R. (2017). Bioavailability \& absorption of Iron and Anemia. Indian Journal of Community Health, 29(4), 453-457.

Kruger, J., Mongwaketse, T., Faber, M., van der Hoeven, M., \& Smuts, C. M. (2015). Potential contribution of African green leafy vegetables and maize porridge composite meals to iron and zinc nutrition. Nutrition, 31(9), 1117-1123. https://doi.org/10.1016/j.nut.2015.04.010

Lee, S., Choi, Y., Jeong, H. S., Lee, J., \& Sung, J. (2018). Effect of different cooking methods on the content of vitamins and true retention in selected vegetables. Food Science and Biotechnology, 27(2), 333-342. https://doi.org/10.1007/s10068-017-0281-1

Libert, B. (1981). Rapid determination of oxalate acid by reverse-phase high performance liquid chromatography. Journal of Chromatography, 210, 540-543. https://doi.org/10.1016/S0021-9673(00)80349-0

Lion, R., Arulogun, O., Titiloye, M., Shaver, D., Jain, A., Godwin, B., Sidibe, M., Adejumo, M., Rosseel, Y., \& Schmidt, P. (2018). The effect of the "Follow in My Green Food Steps" programme on cooking behaviours for improved iron intake: a quasi-experimental randomized community study. International Journal of Behavioral Nutrition and Physical Activity, 15(79), 1-14. https://doi.org/10.1186/s12966-018-0710-4

Luten, J., Crews, H., \& Flynn, A. (1996). Interlaboratory trial on the determination of the In Vitro iron dialysability from food. Journal of the Science of Food and Agriculture, 72(4), 415-424. https://doi.org/10.1002/(SICI)1097-0010(199612)72:4<415::AID-JSFA675>3.0.CO;2-X

Miglio, C., Chiavaro, E., Visconti, A., Fogliano, V., \& Pellegrini, N. (2008). Effects of different cooking methods on nutritional and physicochemical characteristics of selected vegetables. Journal of Agricultural and Food Chemistry, 56(1), 139-147. https://doi.org/10.1021/jf072304b

Musotsi, A., Makokha, A., Abukutsa-Onyango, M., \& Kilonzi, S. M. (2019). Quantitative Changes of Ascorbic acid and Beta carotene in African nightshade ( S olanum nigrum ) and Spider plant ( Cleome gynandra ) due to traditional cooking methods used in western Kenya. Journal of Food and Nutritional Sciences Research, $1(1), 51-63$.

Musotsi, A. A., Sigot, A., \& Abukutsa-Onyango, M. (2005). African Indigenous Vegetables Recipe Documentation and their role in food security. Proceedings of the Third Horticulture Workshop OnSustainable Horticultural Production in the Tropics.

Musotsi, A. A. (2017). Meal attitudes and practices influencing consumption of African Indigenous Vegetables in Kenya. African Journal for Horticultural Sciences, 12, 1-7.

Musotsi, A. A., Abukutsa-Onyango, M., \& Makokha, A. (2017). Changing food consumption habits: A Case of African Indigenous Vegetables for Food and Nutrition Security in Kakamega County, Western Kenya. African Journal of Horticultural Sciences, 12, 30-39.

Natesh, N. H., Abbey, L., \& Asiedu, S. (2017). An Overview of Nutritional and Antinutritional Factors in Green Leafy Vegetables. Horticulture International Journal, 1(2), 1-9. https://doi.org/10.15406/hij.2017.01.00011

Nomkong, R. F., Ejoh, R. A., Dibanda, R. F., \& Gabriel, M. N. (2019). Bioavailability of Iron and Related Components in Cooked Green Leafy Vegetables Consumed in Cameroon. pp. 1096-1111. https://doi.org/10.4236/fns.2019.109079

Oluoch, M. O., Habwe, F. O., Ngegba, J. B., \& Koskei, K. R. (2012). Food Preparation and Processing Methods on Nutrient Retention and Accessibility in Selected Indigenous Vegetables from East Africa.

Platel, K., \& Srinivasan, K. (2015). Bioavailability of micronutrients from plant foods: An update. Critical Reviews in Food Science and Nutrition, 56(10), 1608-1619. https://doi.org/10.1080/10408398.2013.781011

Popova, A., \& Mihaylova, D. (2019). Antinutrients in Plant-based Foods: A Review. The Open Biotechnology Journal, 13(1), 68-76. https://doi.org/10.2174/1874070701913010068

Rodriguez-Ramiro, I., Dell'Aquila, C., Ward, J. L., Neal, A. L., Bruggraber, S. F. A., Shewry, P. R., \& Fairweather-Tait, S. (2019). Estimation of the iron bioavailability in green vegetables using an in vitro digestion/Caco-2 cell model. Food Chemistry, 301(July), 125292. https://doi.org/10.1016/j.foodchem.2019.125292

Rodriguez, D. (2001). A Guide to Carotenoid Analysis in Foods. In Life Sciences. 
Rothwell, J. A., Medina-Remón, A., Pérez-Jiménez, J., Neveu, V., Knaze, V., Slimani, N., \& Al., E. (2015). Effects of food processing on polyphenol contents: A systematic analysis using phenol-explorer data. Molecular Nutrition \& Food Research, 59(1), 160-170. https://doi.org/10.1002/mnfr.201400494

Schweiggert, R. M., \& Carle, R. (2017). Carotenoid deposition in plant and animal foods and its impact on bioavailability. Critical Reviews in Food Science and Nutrition, 57(9), 1807-1830. https://doi.org/10.1080/10408398.2015.1012756

Shija, A. E., Massaga, J. J., Rumisha, S. F., Oriyo, N. M., \& Kilima, S. P. (2019). Effect of Moringa Oleifera leaf powder supplementation on reducing anemia in children below two years in Kisarawe. Food Science \& Nutrition, 7(April), 2584-2594. https://doi.org/10.1002/fsn3.1110

Singh, A., Bains, K., \& Kaur, H. (2016). Effect of inclusion of key foods on in vitro iron bioaccessibility in composite meals. Journal of Food Science and Technology, 53(4), 2033-2039. https://doi.org/10.1007/s13197-015-2154-z

Singh, P., \& Prasad, S. (2018). Determination of ascorbic acid and its influence on the bioavailability of iron, zinc and calcium in Fijian food samples. Microchemical Journal, 139(2017), 119-124. https://doi.org/10.1016/j.microc.2018.02.019

Suzana, D., Suyatna, F. D., Andrajati, R., Sari, S. P., \& Mun, A. (2017). Effect of Moringa oleifera Leaves Extract Against Hematology and Blood Biochemical Value of Patients with Iron Deficiency Anemia. Journal of Young Pharmacists, 9(1s), 79-84. https://doi.org/10.5530/jyp.2017.1s.20

Traoré, K., Parkouda, C., Savadogo, A., Ba/Hama, F., Kamga, R., \& Traoré, Y. (2017). Effect of processing methods on the nutritional content of three traditional vegetables leaves: Amaranth, black nightshade and jute mallow. Food Science and Nutrition, 5(6), 1139-1144. https://doi.org/10.1002/fsn3.504

Yang, R., Chang, L., Hsu, J., Weng, B. B. C., Palada, C., Chadha, M. L., \& Levasseur, V. (2006). Nutritional and Functional Properties of Moringa Leaves - From Germplasm, to Plant, to Food, to Health. pp. 1-9.

Yu, L., Peng, X., Yang, C., Liu, Y., \& Fan, Y. (2002). Determination of Oxalic Acid in Plant Tissue and Root Exudate by Reversed Phase High Performance Liquid Chromatography. Chinese Journal of Analytical Chemistry, 30, 1119-1122.

Zhao, C., Liu, Y., Lai, S., Cao, H., Guan, Y., ... Xiao, J. (2019). Effects of domestic cooking process on the chemical and biological properties of dietary phytochemicals. Trends in Food Science and Technology, 85, 55-66. https://doi.org/10.1016/j.tifs.2019.01.004

\section{Copyrights}

Copyright for this article is retained by the author(s), with first publication rights granted to the journal.

This is an open-access article distributed under the terms and conditions of the Creative Commons Attribution license (http://creativecommons.org/licenses/by/4.0/). 